\title{
ASSESSMENT OF ECOSYSTEMS AND ECOSYSTEM SERVICES FOR SUSTAINABLE LAND USE MANAGEMENT IN LATVIA
}

\author{
Elina Konstantinova $^{1}$, Liga Brunina ${ }^{2}$, Aija Persevica ${ }^{2}$, Inga Honavko ${ }^{3}$ \\ ${ }^{1}$ Ventspils University College, Latvia; ${ }^{2}$ Association Baltic Coasts, Latvia; \\ ${ }^{3}$ Nature Conservation Agency, Latvia \\ elina_konstantinova@inbox.lv, liga.brunina@gmail.com, aija.persevica@baltijaskrasti.lv, \\ inga.honavko@daba.gov.lv
}

\begin{abstract}
Assessment of ecosystem services has been set a strategically important role in the European Union countries, including it to the EU Biodiversity Strategy to 2020. The EU Biodiversity Strategy determines that "Member States, with the assistance of the Commission, will map and assess the state of ecosystems and their services in their national territory by 2014, assess the economic value of such services, and promote the integration of these values into accounting and reporting systems at EU and national level by 2020". There is increased attention of science and practice to ecosystem services last decade and it has led also to an increased interest in both the public and private sectors to develop and apply approaches for evaluating ecosystem services in real-world decision-making concerning sustainable land use, including agriculture and renewable energy sector. There are already a lot of decision support systems already which provide advice and knowledge, but they are not yet integrated into everyday decision-making, mainly because they do not readily fit into land use planning and management processes in practice. The aim of the paper is to present and discuss the approach for ecosystem services(ES) assessment for sustainable land use planning and management. There will be presented the case study for two territories in Latvia, where ecosystem services assessment was implemented - biophysical indicators are developed and assessed by experts. The focus is placed on determining appropriate ES and indicators for assessment and way of integration of ES assessment in land use management. This experience can be transferred to agricultural land and presents a different approach for sustain agricultural productivity and resilience.
\end{abstract}

Keywords: ecosystem services assessment, land use planning, integrated planning, decision making.

\section{Introduction}

Ecosystem services (ES) are defined as "the benefits provided by ecosystems to humans" [1]. For sustainable development, we must find a balance between the exploitation of natural resources to reach socio-economic development goals, and conserving ecosystems and their services for future livelihoods and well being. The ecosystems have more rapidly changed over the past 50 years. It is a challenge to meet the growing demands for provisioning services as fresh water, timber, food, fibre and fuel at the same time reducing the impact on environment. It can lead to decrease of benefits which we can obtain of ecosystems in future. [1]. There are alarming findings, for example, that the exploitation of nature resources has led to increased social and economic costs and will increase in accelerating pace in future if we continue to manage as usual.

The mapping and assessment of ecosystems and their services is an important action in the EU for achievement of biodiversity objectives, and to inform the development and implementation of related policies on climate, agriculture, forest, water, marine and regional and local land use planning. The European Biodiversity Strategy to 2020 includes six targets, which cover the full implementation of the EU nature legislation, protection of ecosystems and the ecosystem services, implementation of more sustainable agriculture and forestry, management of fish stocks, control on invasive alien species, and larger focus on measures to prevent a global biodiversity loss. [2] Target 2 of the Strategy, mainly aims to maintain and enhance ecosystems and their services by establishing green infrastructure and restoring at least $15 \%$ of degraded ecosystems. There are three concrete actions for achieving Target 2 :

- action 5 - promoting the knowledge on ecosystems and ecosystem services;

- action 6 - setting priorities to restore ecosystems and promoting the use of green infrastructure;

- action 7 - implementing initiatives to ensure that there are no net loss of biodiversity and ES [2].

Under Action 5 each of the EU Member States must map and assess the state of ecosystems and their services on their national territory. Mapping means the ecosystems spatial distribution, 
biophysical assessment and quantification of their condition and the services they supply. It requires the use of spatial data and indicators. Assessing means to assess the demands and potential of ES provided by ecosystems in biophysical and economic terms and to translate and introduce this scientific evidence into clear information for policy and decision making, e.g., through maps, indicators, narratives and graphs [3].

Almost all economic sectors and their outputs directly or indirectly depend in some way on ecosystem services [4]. A lot of ES, mainly supporting and regulating services, for example, nutrient cycling, pest regulation and pollination are directly related with sustainable agricultural productivity. Agriculture is a major land use in the EU Member states and it covers about $47 \%$ of the EU land surface. The European Biodiversity Strategy to 2020, Target 3 is directed to integrate the biodiversity concerns into the development and implementation of the EU Agriculture and Forestry policy [2]. Agroecosystems are providing a lot of ecosystem services, first, they provide food and regulation of soil and water quality, carbon sequestration, and support for landscape and cultural services, etc. It is important to ensure the healthy functioning of ecosystems in intensify agriculture activities to meet the growing demands for food and water in future. Also climate change has an important role, which has impact on the key functions, such as pollination and pest regulation services [5]. Agriculture, depending on management practices, can cause also ecosystem disservices, for example, invasive alien species, nutrient runoff, GHG emissions, loss of priority habitats, sedimentation of waterways and pesticide distribution. As more effective approaches for ecosystem services assessment and valuation become available, there increases the potential for "win-win" scenarios for sustainable land use management [6].

The aim of the paper is to present and discuss the approach for mapping ecosystems and their services in Latvia- two coastal pilot implementation areas. Although the research was made for coastal areas, the basic principles can be transferred for agriculture land and the introduced method can be effectively used for sustainable agricultural land use management. The paper focuses on verified mapping methodology appropriate for specific conditions of Latvia introduced with developed indicators for ecosystem services biophysical assessment. The paper includes discussion of results and methodology challenges and their resolving approaches.

\section{Materials and methods}

The case study of ES assessment in coastal areas of Latvia is related with the EU supported project "LIFE Ecosystem Services" started in 2014. The objective of ES assessment in the framework of the project is to promote sustainable land use planning and decision making based on the results of mapping and assessment of coastal ecosystems. The project introduces an innovative approach to the conservation of nature values, through balancing these values with social and economic considerations.

Two pilot areas in the coastal zone - Jaunkemeri and Saulkrasti - have been selected to test the approach of mapping and assessing the ES for the Latvian coastal conditions. Pilot area "Jaunķemeri" is located within the city and is part of Kemeri national park. It includes sandy beach and biologically valuable habitat of EU importance - wooden dunes. The area is not much transformed and relatively poorly visited $(90,85$ ha). Pilot area "Saulkrasti" is located in Saulkrasti municipality. It includes sandy beach and biologically valuable habitat of EU importance - wooden dunes and remarkable cultural and nature monument - White Dune. The well maintained nature object is frequently visited and subjected to excessive anthropogenic pressure and erosion (132,86 ha) [7].

At the beginning, the methodology for mapping and assessment of ES was developed. For ES mapping, the methodology introduces the assessment approach and a related ES assessment matrix developed by B. Burkhard et al, 2009, 2012 and 2014[8;9;10]. The matrix or so called spreadsheet method provides a quick output in a spatial explicit manner and can involve different stakeholder/expert perceptions about ES. Five steps were carried out to map and assess ES in Jaunkemeri and Saulkrasti pilot areas (Figure 1).

For the ecosystem quality assessment, the national methodology on the species and habitat mapping was used. Structure, functions and processes as well as species occurrence in the habitats has been assessed. 


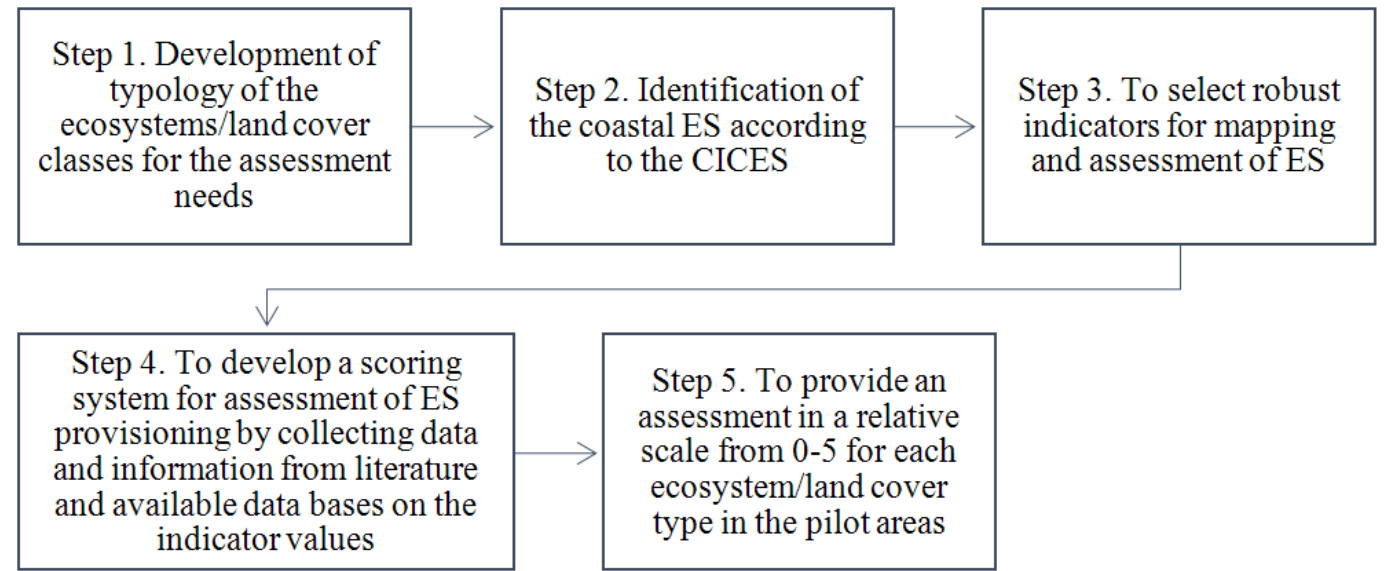

Fig. 1. ES mapping and assessment steps

The ecosystem services identification and classification was based on the Common International Classification of Ecosystem Services (CICES) considering information about the structure of ecosystems and expert knowledge about them. The assessment of the ES was performed based on identified indicators and the assigned values. Expert method to identify and make biophysical assessment of ecosystem services was used in combination with real data, for example gained within ecosystem quality assessment (habitats assessment) and real forestry data. Experts of different fields were involved and worked on more than 20 indicators. Each ES is described by one or more environmental or social indicator or index. For each of the identified geospatial unit the value of ecosystem service is specified.

There was introduced a 5 point scoring system for EP assessment within the case study: 0- ES is not provided; 1 - ES has very low value; 2 - ES has low value; 3 - ES has moderate value; 4- ES has high value; 5 - ES has very high value. The individual scale and interpretation was defined by the relevant expert elaborating an indicator for the EP assessment. The 5 point scale was designed based on the values of the Latvian conditions in ecosystems and environment, thus to ensure replicability in other parts of the coastal zone of Latvia as far as possible. The developed scheme allows to enhance the assessment by integrating exact site specific values when available. The development of indicators was documented in single indicator sheets [11].

The assessment values were used to create a map for each ES as well as to generate a multi -layer map of EP provided as a sum of different services. To produce the aggregated values for each pilot area, an index was calculated for each spatial unit as a sum of the average assessment values of each ES section (provision, regulation and cultural). The section's average values were calculated to reduce an influence of the number of indicators on the total ES value (1).

$$
E P_{i}=E P_{A}+E P_{R}+E P_{K},
$$

where $E P_{i}$ - total ecosystem service assessment

$E P_{A}$ - average assessment value of provision ecosystem services

$E P_{R}-$ average assessment value of regulating ecosystem services

$E P_{K}$ - average assessment value of cultural ecosystem services (Baltic Environmental Forum, 2016).

Finally, a matrix for multi-layered ecosystem services assessment and a multi-layer map for each pilot implementation area were developed.

\section{Results and discussion}

According to the overall ES assessment the forest ecosystem has been assessed as most valuable, followed by sandy beach, dunes and river ecosystems. The ES mapping and assessment in Jaunkemeri and Saulkrasti pilot areas resulted with selected and assessed 23 ES classes based on the Common International Classification of Ecosystem Services (CICES). The indicator based approach was used to describe the current status as well as to present a change in ES supply. The ES assessment was 
provided for each ES individually, filling in the consolidated multi-layer ES assessment matrix as well as presented spatially in the developed of ES assessment maps(Figure 2). Regarding ecosystem quality assessment, the overall conclusion is that the latter habitats are most threatened in both pilot areas.
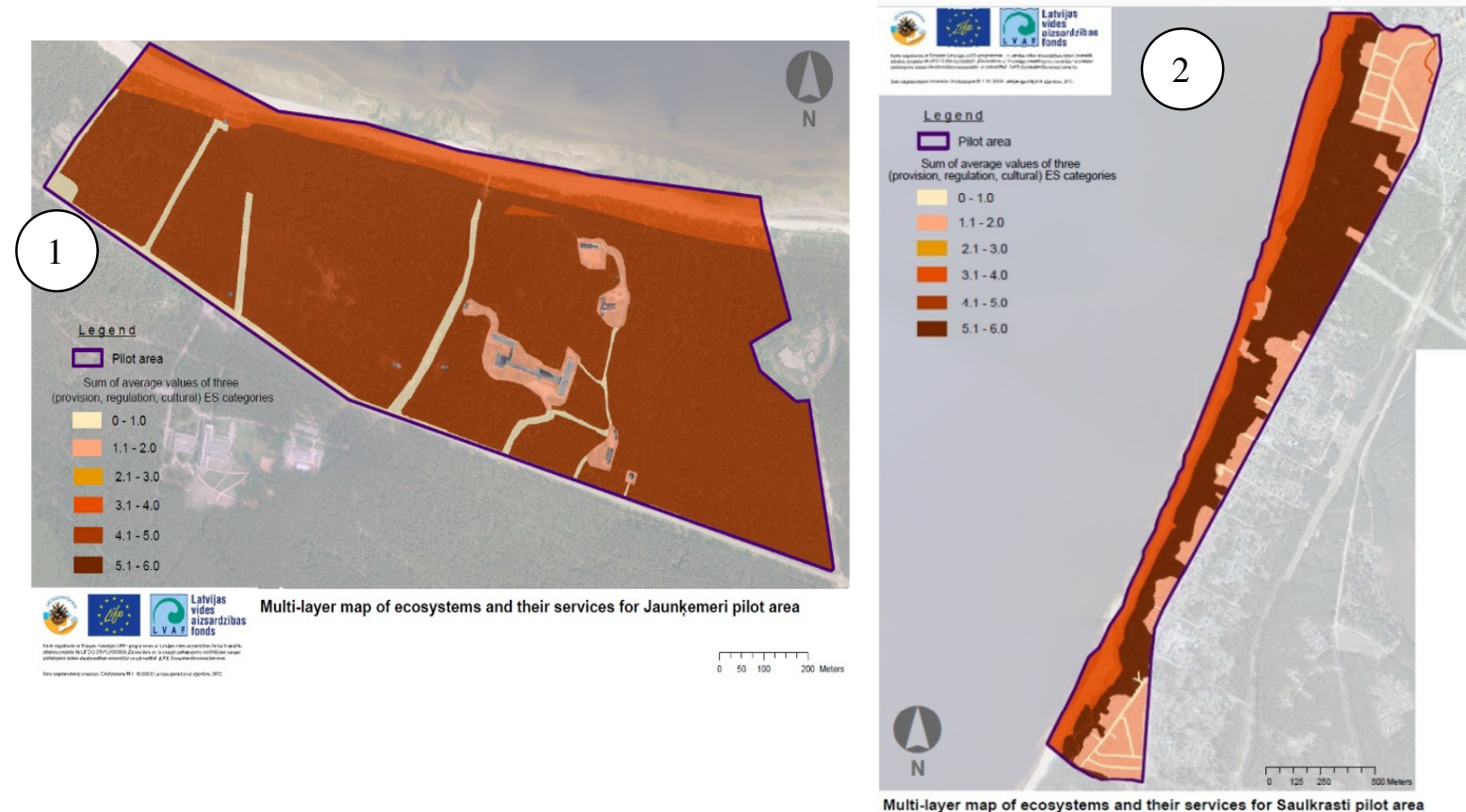

Fig. 2. Aggregated assessment of ES pilot areas: 1 - Jaunķemeri; 2 - Saulkrasti

For introducing the ES assessment for sustainable land use management, there were developed two development scenarios against the current status of the land use in the both pilot areas. Saulkrasti and Jurmala are popular recreation and tourism destinations, therefore, the main controversial interests are - nature conservation versus tourism development.

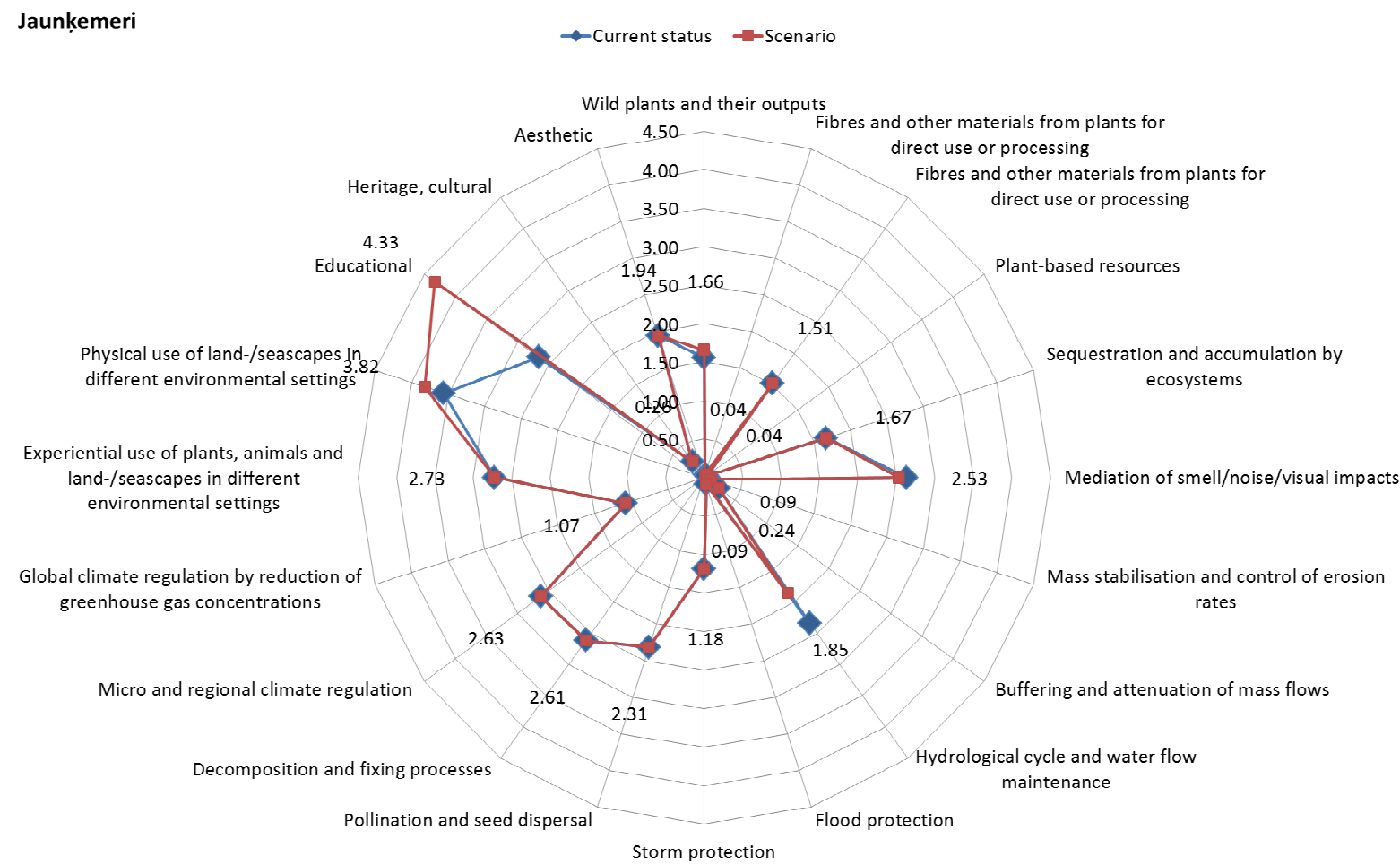

Fig. 3. Spidergram on ES assessment on the current status and the change due to implementation of the scenario in Jaunkemeri pilot area [11] 
The implementation of the activities as described in the scenarios would cause a pressure - new infrastructure, an increase of tourists and recreational users - which result in changes of ecosystems and their quality. The impact of the scenarios on the ES was assessed by applying the same approach as for the assessment of the current status of the ES. The expert team prepared another matrix, which illustrated a change in the ES values due to establishment of the Kemeri Resort Park in Jaunkemeri pilot area and the Nature Design Park in Saulkrati pilot area. The experts assessed a change in ES supply if the developed scenarios would be implemented in both pilot areas. In order to assess the impact caused by the scenario on each ES class an average weighted assessment value was calculated by relating the ES value with an area covered by the respective land cover/ecosystem in the pilot area.

The assessment results show that no change in majority of ES is detected due to the impact of the proposed development scenarios (Figure 3,4). The potential impact could be insignificant as the assigned assessment values do not change.

The cultural ES are an exception - an increase is expected in both areas. In turn, few regulating ES would decrease in Jaunkemeri area - mediation of noise impacts, hydrological cycle and water flow maintenance. The scenario would also have an impact on the yield of wild berries; the benefits would increase due to reduced density of stands in forests.

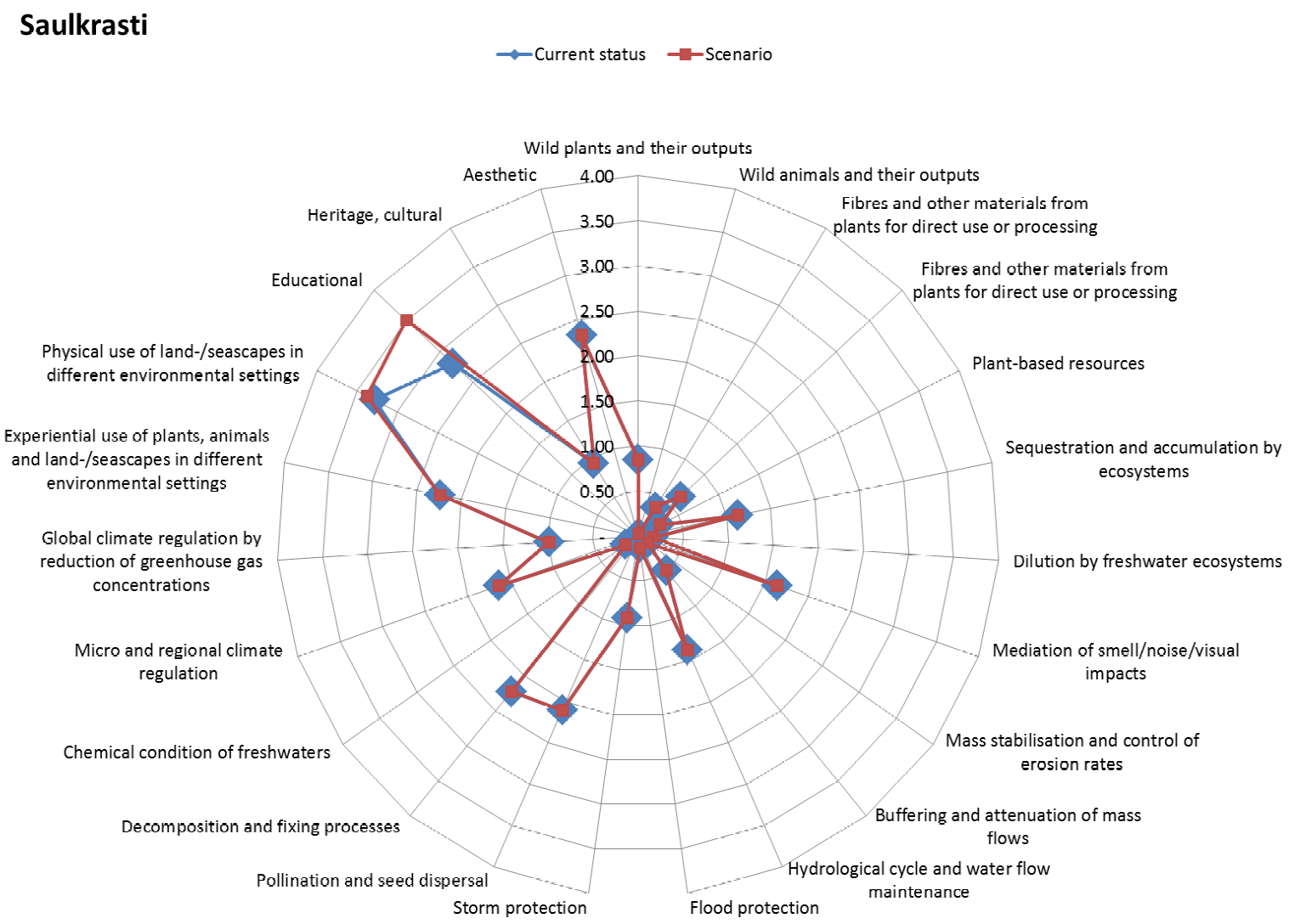

Fig. 4. Spider gram on ES assessment on the current status and the change due to implementation of the scenario in Saulkrasti pilot area [11]

\section{Conclusions}

According to the overall ES assessment within the case study, the forest ecosystem has been assessed as most valuable, followed by sandy beach, dunes and river ecosystems. Regarding ecosystem quality assessment, the overall conclusion is that the latter habitats are most threatened in both pilot areas.

The method described in the paper provides an opportunity to describe spatially distribution and importance of the ES in the given area, to identify the most valuable areas regarding the ES supply as well as to evaluate the impact on the ES supply for development scenarios. This method can be 
applied also for assessing agroecosystem services. It would also allow to compare different management practicesand evaluate trade-offs with other land management options. ES assessment can encourage agrosystem managers and farmers to protect ecosystems and deliver more ecosystem services through better practices and management of crops, livestock, forests and fisheries, and conservation of protected habitats and species.

In common, the study shows that the key challenges with the ES assessment methodology are:

- identifying and prioritizing which ecosystems and services to map and assess;

- accuracy of mapping and assessment depend on time and material resources and data availability;

- availability of relevant data for reliable indicators for ES assessment;

- guiding and integration of ES assessment in planning documents and decision making.

It is important and necessary to understand the biophysical aspects of ecosystem services, but it is not fully sufficient for improving the management of ES in different sectors including tourism and agriculture. Therefore, the next step is economic valuation of ES and integration it into sustainable land use and decision making.

\section{Acknowledgement}

The research underlying this manuscript has been conducted within LIFE "EcosystemServices" (LIFE13 ENV/LV/000839)project, co-financed by the European Union.

\section{References}

1. MA (Millennium Ecosystem Assessment).Ecosystems and Human Well-being: Synthesis. 2005, Island Press, Washington, D.C.

2. European Commission. Our life insurance, our natural capital: An EU biodiversity strategy to 2020. COM, 2011,Brussels.

3. Maes J., Liquete Camino etc. An indicator framework for assessing ecosystem services in support of the EU Biodiversity Strategy to 2020. Ecosystem Services, Volume 17, February 2016, pp. 14-23.

4. Kosmus M., Renner I., Ullrich S.Integrating Ecosystem Services into Development. Planning A stepwise approach for practitioners based on the TEEB approach, 2012, Deutsche Gesellschaft für Internationale Zusammenarbeit (GIZ) GmbH.

5. Ecosystems Services Sustain Agricultural Productivity and Resilience. Food and Agriculture Organization of the United Nations (FAO) Rome, 2008.

6. Power A.G. Ecosystem services and agriculture: tradeoffs and synergies. Philosophical Transactions of the Royal Society No. 365, 2010, pp. 2959-2971.

7. Konstantinova E., Brunina L., Persevica A. Necessity of mapping and assessment of ecosystem and their services in planning and decision making process. International scientific conference 'Society. Integration. Education. May 27th - 28th, 2016, Proceedings, Latvia, Volume IV, Rēzekne, 2016. Thomson Reuters Web of Science ISSN 1691-5887.

8. Burkhard B., Kroll, F., Müller, F., Windhorst, W. Landscapes' Capacities to Provide Ecosystem Services - a Concept for Land-Cover Based Assessments. Landscape Online 15, 2009, pp. 1-22.

9. Burkhard B., Kroll F., Nedkov S., Müller F. Mapping supply, demand and budgets of ecosystem services. Ecological Indicators 21, 2012, pp.17-29.

10. Burkhard B., Kandziora M., Hou Y., Müller F. Ecosystem Service Potentials, Flows and Demands - Concepts for Spatial Localisation, Indication and Quantification. Landscape online 34, 2014, pp. 1-32.

11. Baltic Environmental Forum. Mapping and Assessment of Ecosystem Services in Jaunkemeri and Saulkrasti Pilot Areas within the "LIFE EcosystemServices"(LIFE13 ENV/LV/000839) project Identification No. DAP 2015/51 LIFE, [online] [20.03.20017]. Available at:

http://ekosistemas.daba.gov.lv/public/eng/ 